Check for updates

Cite this: RSC Adv., 2019, 9, 39709

Received 21st September 2019 Accepted 26th November 2019

DOI: 10.1039/c9ra09170j

rsc.li/rsc-advances

\title{
A new safranin based three-component photoinitiating system for high resolution and low shrinkage printed parts via digital light processing†
}

\author{
Atefeh Nejadebrahim, ${ }^{a}$ Morteza Ebrahimi, (D) *a Xavier Allonas, (D) *b Céline Croutxé- \\ Barghorn, (D) ${ }^{\mathrm{b}}$ Christian Ley ${ }^{\mathrm{b}}$ and Boris Métral ${ }^{\mathrm{b}}$
}

\begin{abstract}
Additive manufacturing or 3D printing has attracted the interest of researchers in industry and academia because of its outstanding features. In this study, a new three-component photoinitiating system (PIS) consisting of safranin $\mathrm{O}\left(\mathrm{SFH}^{+}\right)$, thiol derivatives and diphenyl iodonium salt was used for the free radical photopolymerization of a diacrylate monomer (SR349) in DLP 3D printing. The photoinitiating characteristics of this PIS were evaluated and advantageously compared to those of a conventional PI (TPO) by using RT-FTIR. It is shown that the proposed PIS could be used as an efficient PIS for free radical photopolymerization. In addition, the resolution and shrinkage of printed parts in the presence of this three-component PIS were measured and compared to those printed using TPO as a photoinitiator. The resolution of printed parts was determined by using SEM and profilometry techniques. In addition, photorheometry was used to evaluate the linear shrinkage of samples. Moreover, the initiating mechanism of the three-component PIS was studied by using laser flash photolysis (LFP). A photocyclic mechanism was outlined for the three-component PIS which demonstrated this mechanism would be very beneficial for DLP 3D printing.
\end{abstract}

\section{Introduction}

In the 1980s, three dimensional (3D) printing or additive manufacturing (AM) was first introduced as a technology for fabricating 3D objects using a computer-aided design (CAD) file. ${ }^{1-3}$ Thanks to its ability to produce complex geometries in a simple one-step process, little waste of material, and being user-friendly, the applications of this technology in different fields such as medical implants and prosthetics, ${ }^{4,5}$ digital dentistry, ${ }^{6,7}$ tissue engineering, ${ }^{8,9}$ the aerospace industry, ${ }^{10,11}$ construction $^{12,13}$ and sensors ${ }^{14}$ are growing fast. It is expected that the world's $3 \mathrm{D}$ printing market would experience $18 \%$ growth annually and reach up to 23 billion USD by $2022 .{ }^{15}$

Vat photopolymerization is one of the most popular 3D printing techniques utilizing a light source for solidifying a photopolymer. ${ }^{16,17}$ Digital light processing (DLP), based on vat photopolymerization method, is very similar to lithography and is also known as dynamic mask photolithography. ${ }^{3}$ Build time, oxygen sensitivity and adhesion between different layers are improved in this technique. ${ }^{18,19}$ However, vertical resolution,

${ }^{a}$ Polymer and Color Engineering Dept., Amirkabir University of Technology, $424 \mathrm{Hafez}$ Ave., Tehran, Iran.E-mail: ebrahimi@aut.ac.ir

${ }^{b}$ Laboratory of Molecular Photochemistry and Engineering, University of Haute Alsace, $3 b$ Rue Alfred Werner, 68093 Mulhouse, France

$\dagger$ Electronic supplementary information (ESI) available. See DOI: $10.1039 / \mathrm{c} 9 \mathrm{ra} 09170 \mathrm{j}$ dimensional accuracy, and shrinkage are still the main challenges of DLP 3D manufactured parts. ${ }^{20-22}$ Vertical resolution depends on the penetration depth of incident light into liquid photopolymer. Several researches have studied and tried to solve this challenge by using different types of light absorbers and inhibitors in formulations. ${ }^{23,24}$ Zissi et al. studied the influence of adding a non-reactive absorbing chemical on the depth of cure in a 3D printing system. ${ }^{25}$ They reported that the cure depth and width could be controlled by adjusting the photoabsorber concentration. Choi et al. investigated the effect of different concentrations of Tinuvin ${ }^{\circledR} 327$, as a light absorber, on the quality of fabricated objects. It was demonstrated that not only light absorber concentration but also exposure energy could affect the resolution of complex geometries. ${ }^{26}$ Chin et al. studied the effect of a red-shifted UV absorber (Tinuvin ${ }^{\circledR}$ CarboProtect $($ ) on cure depth and kinetics in visible light initiating resin for 3D printing. They illustrated an enhancement in the geometrical and dimensional accuracy of stereolithography process operating under visible blue light. ${ }^{27}$ However, Zabti et al. showed that the presence of light absorbers such as Tinuvin ${ }^{\circledR} 327$ in formulation increased dimensional error which could be originated from shrinkage. ${ }^{28}$

Shrinkage, as the other main challenge, was studied by several researches. ${ }^{29}$ For example, Stampfl $e t$ al. ${ }^{30}$ and Schoerpf et $a l^{31}$ used monofunctional monomers and chain transfer agents and Chiappone et al. ${ }^{32}$ proposed using acrylate/epoxy hybrid systems to overcome this problem to some extent. 
However, these strategies caused other problems such as deterioration of long-term mechanical properties of photo-cured systems and also the requirement of using dual photoinitiator systems (i.e., radical and cationic photoinitiators), respectively.

In recent years, visible light initiating systems have been highly regarded in order to solve some UV radiation issues such as high heat build-up, safety, and curing of thick samples. ${ }^{33,34}$ However, there is very limited photoinitiator leading to photodissociation in the visible region. ${ }^{35}$ Therefore, using two/threecomponent photoinitiating systems (PIS), consisting of a photosensitizer and one or two coinitiator(s) have been pointed out. In these systems, the active species are usually generated via an electron/energy transfer between a photosensitizer and coinitiator. ${ }^{36}$ The photosensitizer is typically an organic dye such as safranin, ${ }^{37}$ methylene blue, ${ }^{38}$ rose bengal ${ }^{39}$ or ketone sensitizer like isopropyl thioxanthone (ITX). ${ }^{40}$ The second 3 component is an electron or/and a hydrogen donor that is usually an amine or thiol, and the third component is an electron acceptor such as onium salt. ${ }^{\mathbf{4 1}}$

According to previous studies, safranin $\mathrm{O}\left(\mathrm{SFH}^{+}\right)$can be used as a high-performance photosensitizer in two- or threecomponent photoinitiating systems. Several researchers have reported the radical generation ability of safranin in combination with different coinitiators. ${ }^{42-45}$ Therefore, in this study, a threecomponent PIS based on safranin $\mathrm{O}$ was employed in digital light processing 3D printing to investigate the dual function of the dye as photosensitizer and photoabsorber. As mentioned before, the former was responsible for active species production and the latter could play a role in controlling the curing depth and improving the vertical resolution of printed parts. For this purpose, a combination of safranin $\mathrm{O}$, thiol derivative and onium salt was chosen as three-component PIS in an ethoxylated diacrylate system (SR349). In addition, the effect of curing protocol of this PIS on shrinkage was investigated. The performances of this new three-component PIS regarding resolution and shrinkage were compared to those obtained using diphenyl (2,4,6-trimethylbenzoyl) phosphine oxide (TPO) as photoinitiator. Finally, the photochemical mechanisms associated with the generation of the active species in this PIS were investigated.

\section{Experimental}

\section{Materials}

Safranin $\mathrm{O}\left(\mathrm{SFH}^{+}\right)$(dye content $>85 \%$ ), pentaerythritol tetrakis(3mercaptopropionate) (RSH, 95\%), diphenyl (2,4,6-trimethylbenzoyl)phosphine oxide (TPO) and dimethyl sulfoxide (DMSO) were purchased from Sigma-Aldrich. Diphenyliodonium hexafluorophosphate $\left(\mathrm{IOD}^{+}, 98 \%\right)$ was obtained from TCI. Ethoxylated (3) bisphenol A diacrylate (SR349) was obtained from Sartomer. Acetonitrile (99.97\%) and isopropyl alcohol were received from Biosolve. All chemicals were used as received. Chemical structures of the main materials are shown in Table 1.

\section{DLP printing system}

B9Creation V1.2 3D printer (B9Creator Company, USA) was used for printing complex geometries to study the resolution and
Table 1 Chemical structures of used materials

Name Structure

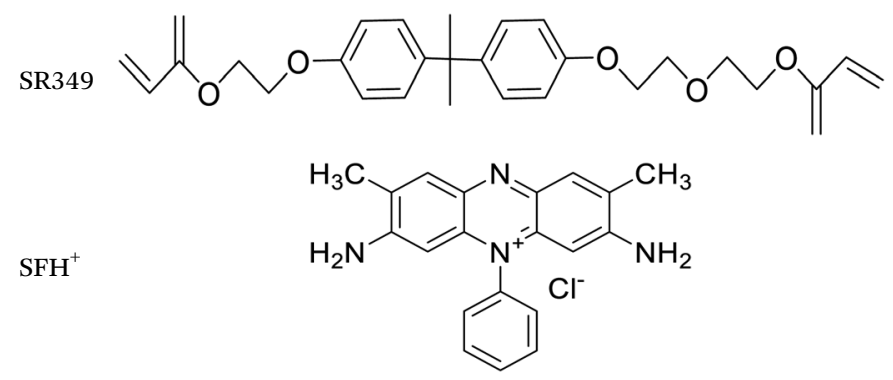

$\mathrm{RSH}$<smiles>O=C(CCS)OCC(COC(=O)CCS)(COC(=O)CCS)COC(=O)CCS</smiles>

$\mathrm{IOD}^{+}$

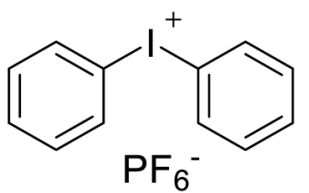

TPO

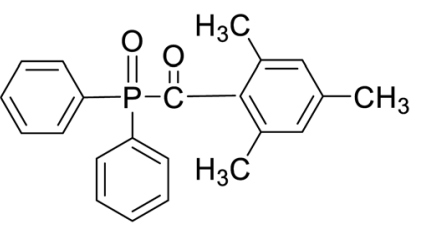

shrinkage properties of the printed parts. The appropriate file format of black and white images of sliced samples was produced by B9Creator software. The radiation was provided by using a modified D912HD projector (Vivitek) with a cut-off filter in the range of $380-800 \mathrm{~nm}$. The radiation intensity measured at the surface of the vat was $170 \mathrm{~mW} \mathrm{~cm}^{-2}$.

The 3D printer had an $X-Y$ resolution of $30 \mu \mathrm{m}$, the layer thickness was adjusted on $20 \mu \mathrm{m}$ and each layer was exposed to radiation for $6 \mathrm{~s}$, while the exposure time for the first two layers was set to be $30 \mathrm{~s}$. Printed parts were submerged in $90 \%$ isopropyl alcohol for less than a minute to wash off the surface from unreacted monomers. The printed parts were air-dried at room temperature before post-curing under a medium pressure mercury lamp for about 60 seconds.

For characterization and comparing the $X-Y$ and $Z$ resolutions of printed samples, a 3D benchmark design was selected from Auto desk Ember website shown in Fig. 1. The minimum size printed accurately in each direction was considered as $X-Y$ and $Z$ resolution of the samples.

Two formulations for 3D printing were prepared, as shown in Table 2. The first one consist of SR349 monomer, which was diluted with 10 phr DMSO and three-component PIS based on $\mathrm{SFH}^{+} / \mathrm{RSH} / \mathrm{IOD}^{+}$. The composition of the three-component PIS was designed according to literature and this sample was named 3KSRD. In the second sample, TPO was used as one of the most commonly used photoinitiators in photoinduced $3 \mathrm{D}$ 


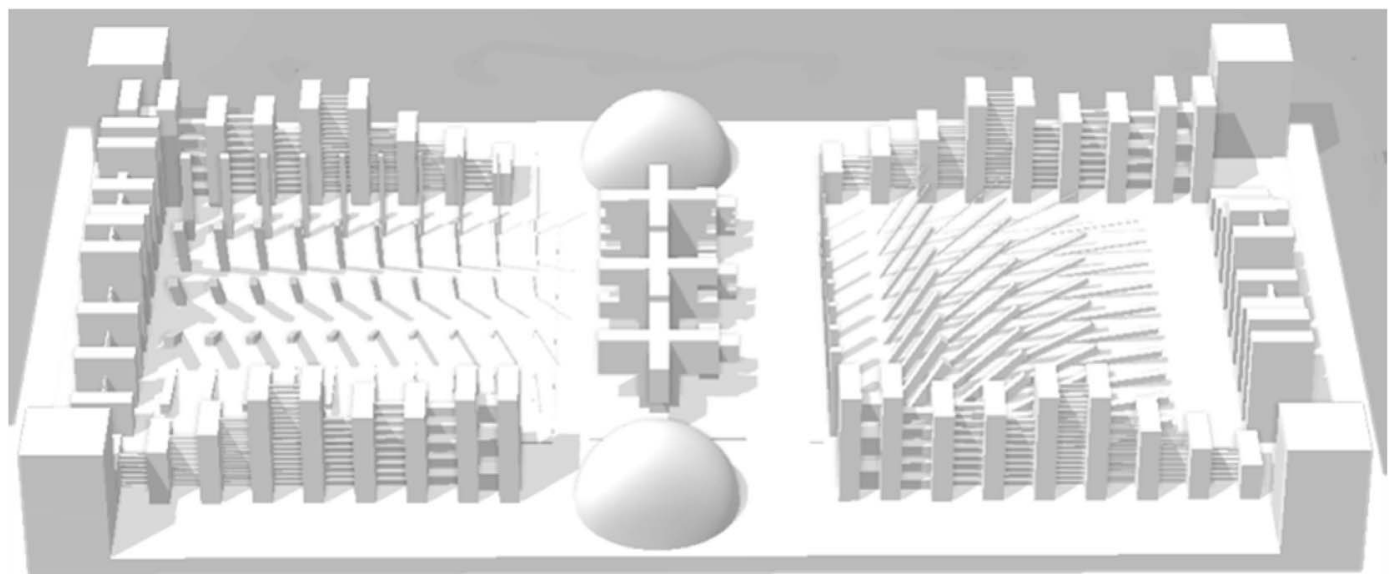

Fig. $13 D$ view of benchmark design used for $X-Y$ and $Z$ resolution.

Table 2 Composition of the 3D printing sample formulation

\section{Sample}

code Composition

3KSRD $\quad$ SR349/DMSO (10 phr $) / \mathrm{SFH}^{+}(0.2 \mathrm{phr}) / \mathrm{RSH}(3 \mathrm{phr}) / \mathrm{IOD}^{+}(3 \mathrm{phr})$ 1KTPO SR349/DMSO (10 phr)/TPO(1 phr)

printing techniques. This sample was named 1 KTPO as a reference to compare the performance of the new proposed PIS with that of a conventional one. ${ }^{46}$ In order to compare the results obtained with $1 \mathrm{KTPO}$ and $3 \mathrm{KSRD}$, the TPO concentration was adjusted to obtain the same final conversion as 3KSRD sample. Therefore, the appropriate concentration of TPO was found to be 1 phr. Worth mentioning that the concentrations of SR349 and DMSO were kept the same to avoid any interference on the printing properties such as resolution, shrinkage and dimensional accuracy.

\section{Characterization and measurements}

Vertex 70 FTIR spectrophotometer (Bruker Optik GmbH, Germany) in its real-time mode was used to study the photopolymerization kinetics of formulations. The resolution of spectra was equal to $4 \mathrm{~cm}^{-1}$. Samples were irradiated by a xenon lamp (Hamamatsu L9566-04) when IR spectra were recorded. It should be mentioned that the irradiation wavelength was adjusted at $\lambda<395 \mathrm{~nm}$ by using a cut-off filter. Light intensity at the sample surface was set to be $230 \mathrm{~mW} \mathrm{~cm}^{-2}$. The reference sample (containing TPO) was irradiated by a $395 \mathrm{~nm}$ LED device (Roithner Laser Technik) which provided $100 \mathrm{~mW} \mathrm{~cm} \mathrm{~cm}^{-2}$ intensity at the surface of the sample. The degree of $\mathrm{C}=\mathrm{C}$ conversion, $C$, was calculated according to eqn (1):

$$
C(\%)=\frac{A_{0}-A_{t}}{A_{0}} \times 100
$$

where $A_{0}$ and $A_{t}$ are the area of the IR absorption band at $1637 \mathrm{~cm}^{-1}$ of samples at the starting point and time $t$, respectively. All spectra were baseline-corrected before the integration with the software OPUS 7.0. To be sure about the reproducibility of the results, each experiment was repeated at least three times. Finally, the rate of photopolymerization, $R_{\mathrm{p}}$, was determined from the slope of the conversion-time profile.

Linear shrinkage measurements of samples were conducted based on Shah et al. method, ${ }^{47}$ by using an MCR 302 rheometer from Anton Paar, which was combined with a light source accessory for the curing of samples. The experimental setup is presented in Fig. 2. The test was performed in the oscillation mode of the rheometer. The smooth aluminum plate was fixed at an initial $0.5 \mathrm{~mm}$ gap and a zero Newton normal force was applied to samples. The samples were irradiated in the same condition as RT-FTIR analysis. The light was directed under a glass plate by using an optical fiber, which would allow the photopolymerization of samples. The shrinkage of sample led to the gap reduction. So the variation of the gap during the photopolymerization would represent the shrinkage according to eqn (2), where the $d_{\text {final }}$ and $d_{\text {initial }}$ are the distance between the glass and aluminum plate at the beginning and end of photopolymerization, respectively.

$$
\text { Shrinkage }(\%)=\left(1-\frac{d_{\text {final }}}{d_{\text {initial }}}\right) \times 100
$$

Scanning electron microscopy (SEM) was performed in order to investigate the quality of printed specimen (FEI Quanta 400 microscope, Thermo fisher scientific, DEU). The imaging was carried out under low vacuum condition.

The size and shape of printed pattern were evaluated by an optical profilometer (Altisurf 500 workstation, Altimet, FRA) equipped with a microforce sensor for solid films.

Cary 4000 UV-vis spectrophotometer (Agilent Technologies, USA) was used to determine the UV-visible spectra of samples at room temperature. Acetonitrile was used as a solvent for the preparation of samples.

Triplet-triplet absorption and photobleaching spectra were measured by using an LP900 laser flash photolysis analyzer (Edinburgh Instruments, UK). The details of the instrument, its accessory, experiment conditions and procedure were reported elsewhere. ${ }^{48}$ It would be noted that the light excitation was 
performed at $\lambda_{\text {exc }}=518 \mathrm{~nm}$ because $\mathrm{SFH}^{+}$has a maximum absorption at this wavelength. The constant of quenching rate of excited states $\left(k_{\mathrm{q}}\right)$ was determined by using a well-known Stern-Volmer equation:

$$
\frac{1}{\tau}=\frac{1}{\tau_{0}}+k_{\mathrm{q}}[\mathrm{Q}]
$$

which $\tau$ and $\tau_{0}$ are the lifetime of triplet state in the presence and absence of quencher $\mathrm{Q}$, respectively.

\section{Results and discussion}

As mentioned before, 1KTPO sample was designed to have the same final conversion as $3 \mathrm{KSRD}$ system. This could be seen in Fig. 3, where the photopolymerization kinetics of the two samples were studied using RT-FTIR technique. However, it should be noted that the polymerization for $1 \mathrm{KTPO}$ sample was found to be four times faster than that for 3KSRD system.

\section{Effect of PIS on resolution}

Most of the TPO based systems contain a UV absorber which increases the absorbance and decreases the penetration depth of light. In this study, no absorber was added to the sample in order to study the intrinsic resolution obtain with the different PIS. $X-Y$ and $Z$ resolutions of both 3 KSRD and 1KTPO samples are gathered in Table 3 as evaluated from the printed benchmark design (Fig. 4). It can be seen that 3KSRD resolution was clearly better than that of $1 \mathrm{KTPO}$ in all directions. This is particularly the case in the $Z$ direction. In that case, it seems that $\mathrm{SFH}^{+}$could successfully control the penetration depth of incident light by its light-absorbing capability. To support this justification, the penetration depth, $D_{\mathrm{p}}$, of the light in the presence of safranin and TPO compound was calculated by using eqn (4). ${ }^{3}$

$$
D_{\mathrm{p}}=\frac{1}{2.3\left(\varepsilon_{\mathrm{I}}[\mathrm{I}]+\varepsilon_{\mathrm{A}}[\mathrm{A}]\right)}
$$

where $\varepsilon_{\mathrm{I}}$ and $\varepsilon_{\mathrm{A}}$ are the molar extinction coefficient of initiator and absorber (when present), respectively, and [I] and [A] are the concentration of initiator and absorber, respectively. Based on the values reported for the molar extinction coefficients in the literature ${ }^{\mathbf{4 5 , 4 9}}$ and keeping in mind that no absorber was used in this study, the $D_{\mathrm{p}}$ of $3 \mathrm{KSRD}$ sample was found to be significantly smaller than that of $1 \mathrm{KTPO}$ (i.e., $40 v s$. $600 \mu \mathrm{m}$ ). It approves that $\mathrm{SFH}^{+}$had a dual-function as photosensitizer and photoabsorber in the system.

Table 3 Dimensional resolution measurements

\begin{tabular}{llll}
\hline Sample & $\begin{array}{l}X \text {-resolution } \\
(\mu \mathrm{m})\end{array}$ & $\begin{array}{l}Y \text {-resolution } \\
(\mu \mathrm{m})\end{array}$ & $\begin{array}{l}Z \text {-resolution } \\
(\mu \mathrm{m})\end{array}$ \\
\hline 1KTPO & 500 & 500 & $>1000$ \\
3KSRD & 100 & 100 & 100
\end{tabular}

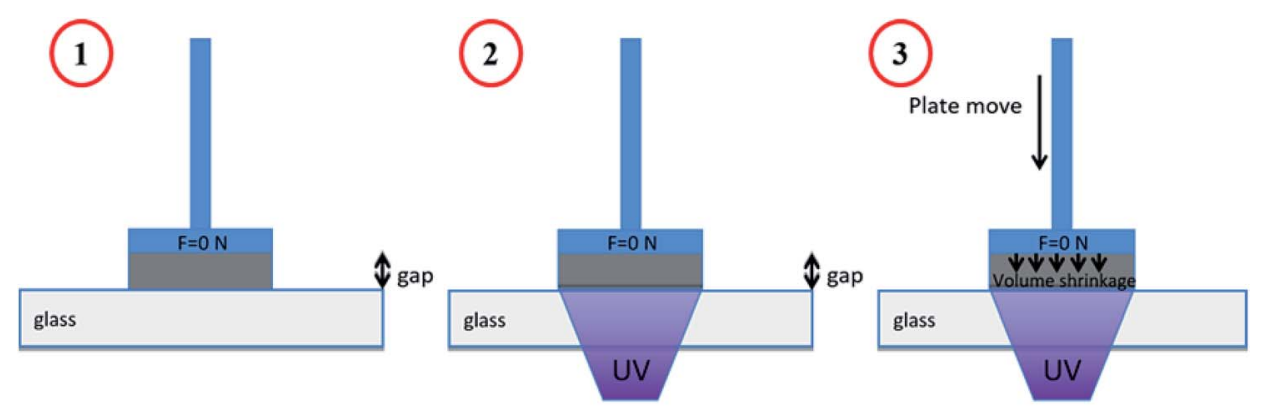

Fig. 2 Schematic representation of the shrinkage measurement apparatus.
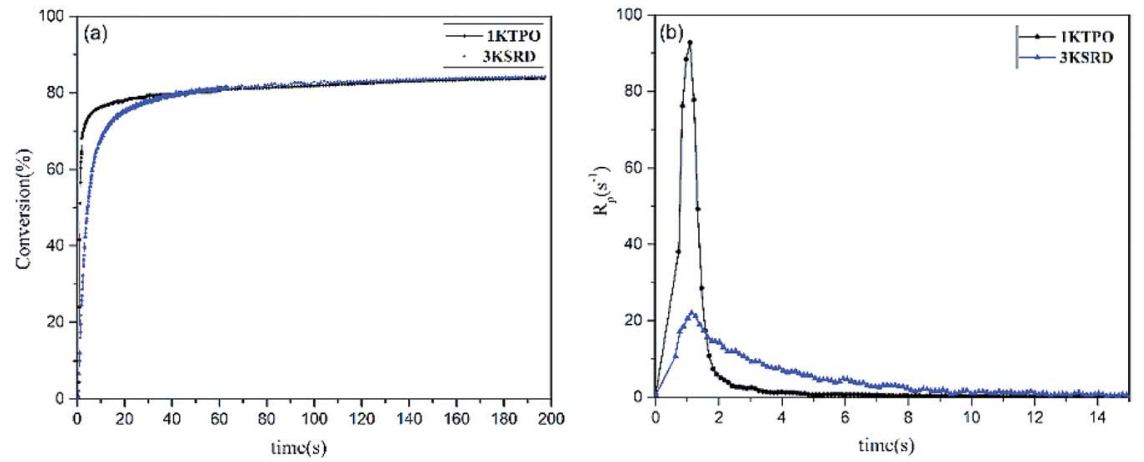

Fig. 3 Comparison of 3KSRD and 1KTPO polymerization: (a) conversion (b) rate of photopolymerization. 

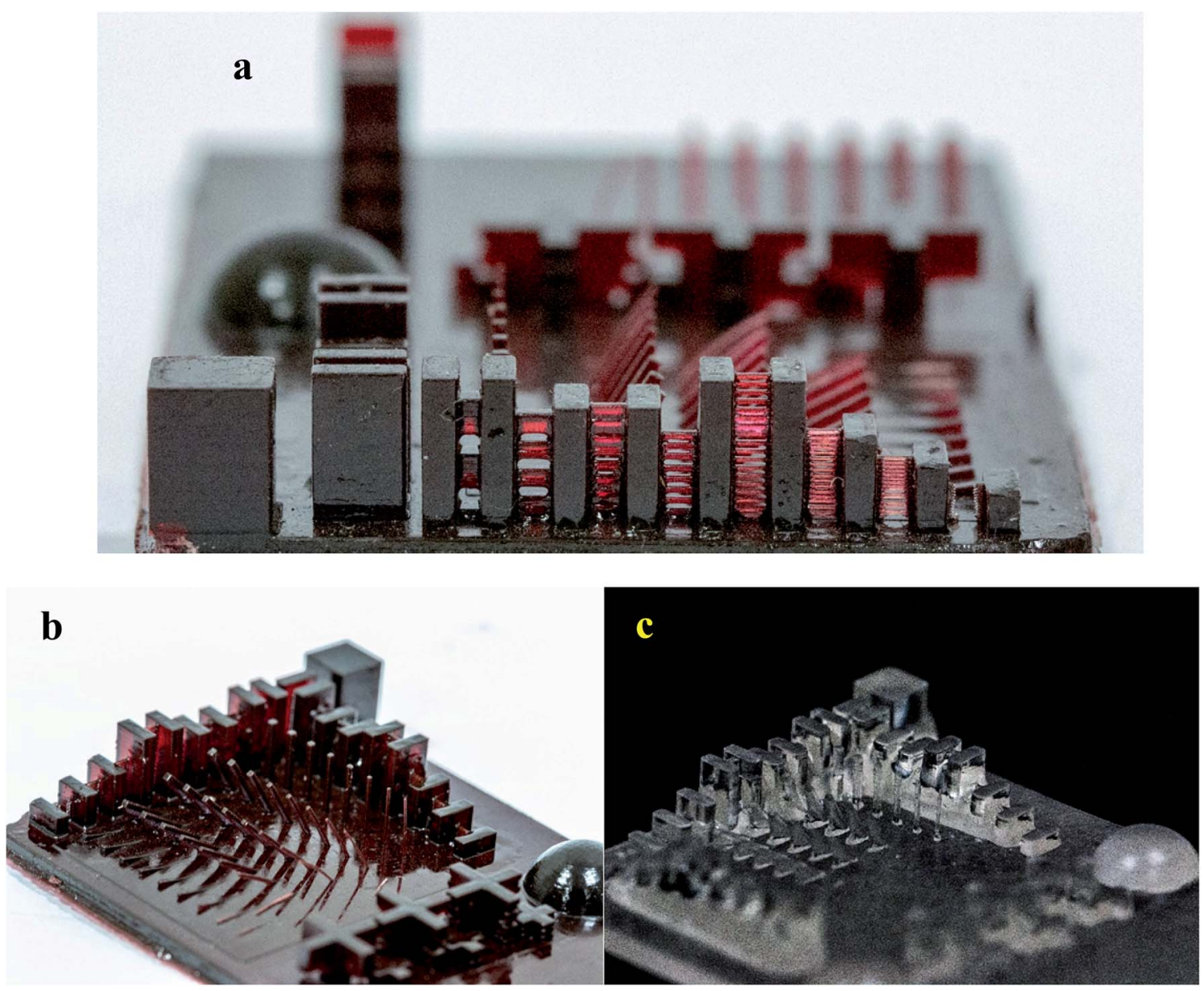

Fig. 4 Photographs of the printed benchmark design for (a) 3KSRD sample (Z-resolution), (b) 3KSRD sample and (c) 1KTPO sample.

\section{Effect of PIS on shrinkage}

As noted earlier, shrinkage in printed parts is an important issue intrinsically due to the free radical photopolymerization. ${ }^{21,28}$ For this reason, the effect of new proposed PIS on the shrinkage was studied by photorheometery technique. As can be seen in Fig. 5, the linear shrinkage of 3KSRD and 1 KTPO were measured to be 0.9 and $4.2 \%$, respectively. It means that the shrinkage of printed part improved significantly when the three-component PIS was used. As the monomer and photopolymerization conditions are almost the same for both samples, different behavior of the two systems could be related to the different photoinitiating systems. In fact, as seen previously in Fig. 3, the polymerization rate of $1 \mathrm{KTPO}$ system was remarkably higher than that for 3KSRD system which led to a higher inhomogeneity and internal stress formation in the cured sample. It seems that this higher inhomogeneity and internal stress caused a more considerable shrinkage in 1KTPO system.

It is worth mentioning that our proposed new threecomponent PIS (i.e., $\mathrm{SFH}^{+} / \mathrm{RSH} / \mathrm{IOD}^{+}$) could provide a softstart curing protocol which caused achieving relatively high conversion and low shrinkage in an appropriate time. In other words, 3KSRD sample with a slow rate of polymerization may facilitate the relaxation of the polymer chain, thereby leading to a lowering of the shrinkage. ${ }^{50,51}$

Considering the high resolution and low shrinkage of 3KSRD sample, the capability of this formulation for the

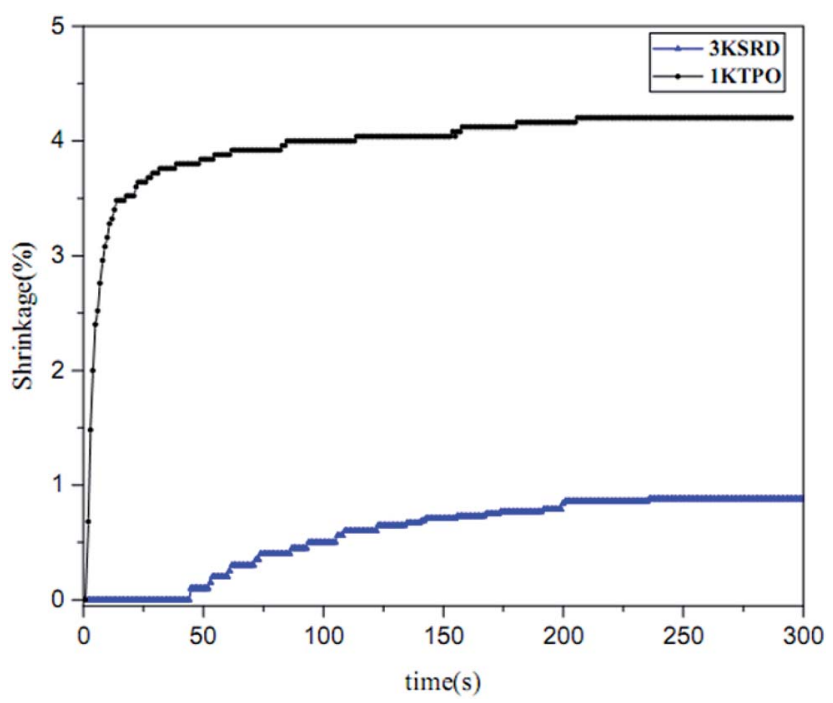

Fig. 5 Effect of PIS on shrinkage. 

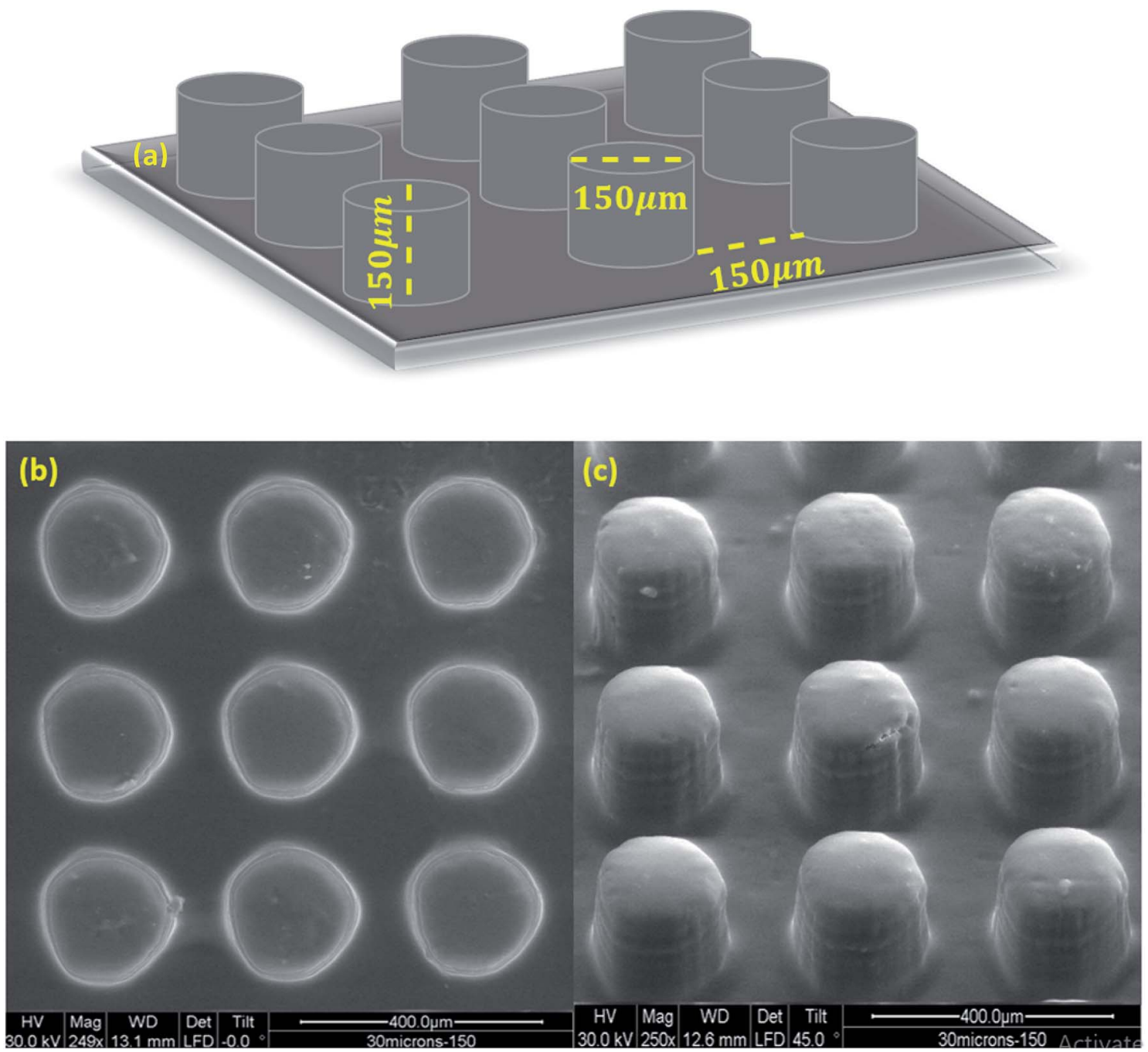

Fig. 6 (a) Schematic image of simple micro-featured pattern, (b) and (c) SEM images of fabricated microstructures by 3KSRD formulation from different angles.

printing of a simple and a complicated (i.e. Eiffel tower) micro-featured pattern was demonstrated. The simple microfeatured pattern included vertical cylinders with $150 \mu \mathrm{m}$ height and $150 \mu \mathrm{m}$ diameter, as shown in Fig. 6a. The pattern was successfully printed with reasonable fidelity. The topography and profilometry of the printed objects were shown in
Fig. 6b, c and 7, respectively. These figures confirmed clearly the dimensional accuracy and high resolution of printing system.

In addition, the photograph of a 3D printed mini-Eiffel tower was depicted in Fig. 8. As can be seen, all the details of the tower were correctly printed.

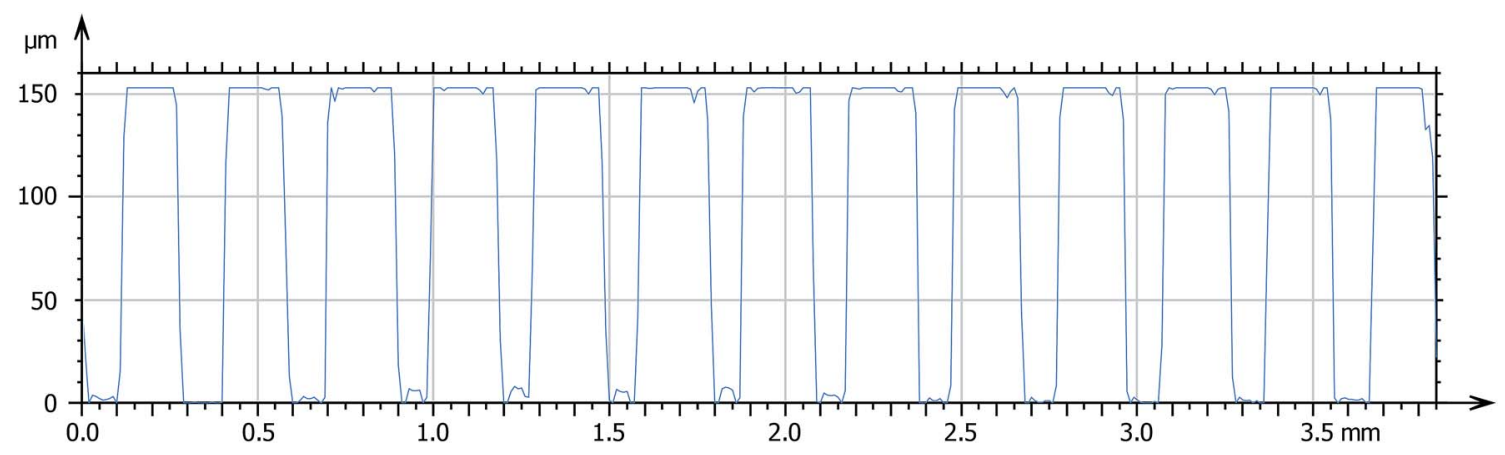

Fig. 7 Lateral profile of printed cylinder from 3KSRD sample with $150 \mu \mathrm{m}$ in height and diameter. 


\section{Photopolymerization kinetics}

The conversion and photopolymerization rate of twocomponent (i.e., 2KSR and 2KSD samples) and threecomponent PIS (i.e., 3KSRD sample) were studied to understand the effect of each coinitiator on the photopolymerization kinetics. ${ }^{48,52}$ The specifications of the samples and the results are compiled in Table 4 and Fig. 9.

The results show that both two-component PIS and the three-component PIS, could initiate the free radical photopolymerization quite effectively. However, the final conversion and polymerization rate of $2 \mathrm{KSR}$ and $2 \mathrm{KSD}$ were found to be considerably lower than that of $3 \mathrm{KSRD}$. It seems that the lower number of created radicals in the two-component PIS in comparison to that of three-component PIS is much lower, thereby leading to slower conversion rates. ${ }^{36,53}$

By looking more closely to the first seconds of polymerization in Fig. 9, it can be seen that there was an inhibition time (about $3.5 \mathrm{~s}$ ) in both 2KSD samples. Indeed, aryl radicals produced by the $\mathrm{SFH}^{+} / \mathrm{IOD}^{+}$reaction in the $2 \mathrm{KSD}$ system were prone to molecular oxygen. By contrast, thiyl radicals in $\mathrm{SFH}^{+}$/ $\mathrm{RSH}$ system are less sensitive to oxygen inhibition and, therefore, lead to lower inhibition time. ${ }^{48}$

In addition, Fig. 10 shows that the maximum rate of polymerization for 3KSRD was found to be three times higher than those for 2 KSR and 2 KSD samples. The higher reactivity of

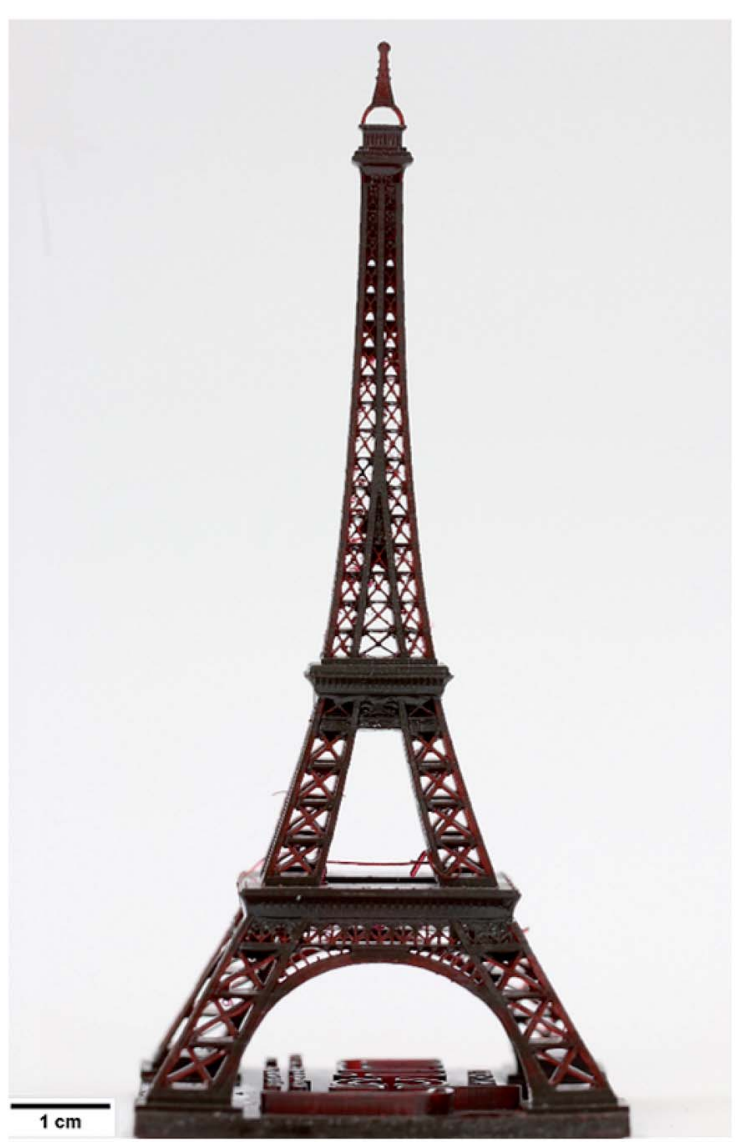

Fig. 8 Photograph of a 3D printed Eiffel tower by using 3KSRD sample.
Table 4 Sample formulation, degree of conversion and polymerization rate

\begin{tabular}{llll}
\hline Sample & $\begin{array}{l}\text { Composition }(\mathrm{phr}) \\
\mathrm{SFH}^{+} / \mathrm{RSH} / \mathrm{IOD}^{+}\end{array}$ & $\begin{array}{l}\text { Conversion } \\
(\%)\end{array}$ & $\begin{array}{l}\text { Maximum rate of } \\
\text { polymerization }\left(\mathrm{s}^{-1}\right)\end{array}$ \\
\hline 2KSD & $0.2 /-/ 3$ & 60 & 5.4 \\
2KSR & $0.2 / 3 /-$ & 64 & 4.1 \\
3KSRD & $0.2 / 3 / 3$ & 84 & 22.0
\end{tabular}

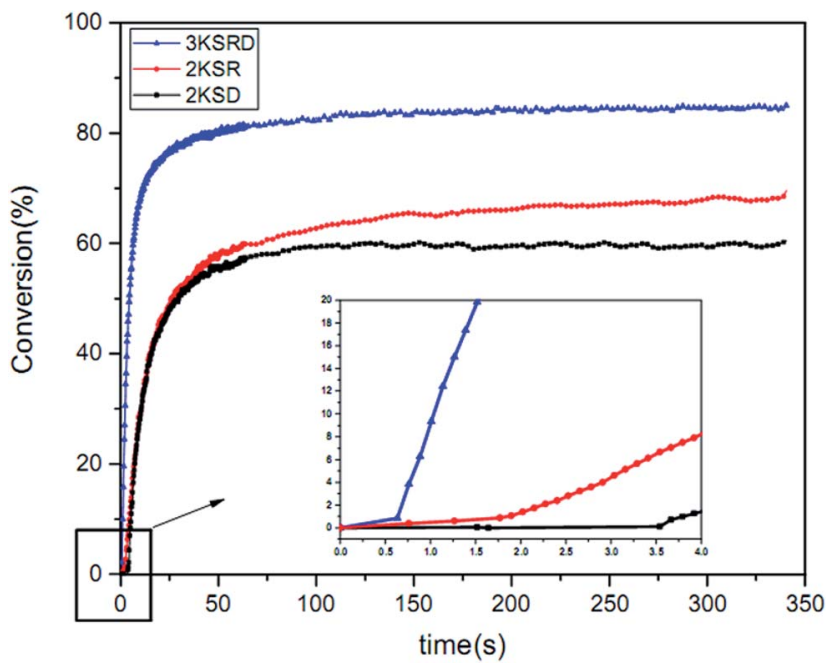

Fig. 9 Conversion vs. time for two- and three-component PIS samples.

three-component system could be explained by different mechanism as deeply studied recently. Indeed, two mechanisms can be introduced to explain these observations. Firstly, both coinitiators can react in parallel with the excited state of the photosensitizer, leading to higher production of radicals. In that case, no synergistic effect occurs and the efficiency is directly related to the excited state quenching efficiency by both coinitiators. ${ }^{51}$ Secondly, sequential reactions in which one of the coinitiators reacted with the excited photoinitiator and then followed by the reaction of the second coinitiator with the photoproduct formed from the photoinitiator in the first reaction. In addition, the ground state photoinitiator was recovered through this second reaction which could absorb the light and react again, leading to a photocyclic initiating system. ${ }^{53}$

\section{Photoinitiation mechanism}

In order to study the photoinitiating mechanisms of two- and three-component PISs, laser flash photolysis (LFP) experiments were performed. At first, the UV-vis spectra of $\mathrm{SFH}^{+}$and the mixture of $\left(\mathrm{SFH}^{+} / \mathrm{RSH} / \mathrm{IOD}^{+}\right)$were measured. As can be seen in Fig. $\mathrm{s} 1, \dagger$ the absorption spectrum of $\mathrm{SFH}^{+}$had a maximum around $520 \mathrm{~nm}\left(\varepsilon=44000 \mathrm{M}^{-1} \mathrm{~cm}^{-1}\right)$ and both coinitiators absorbed in the wavelength less than $375 \mathrm{~nm}$. It was observed that the spectrum of $\mathrm{SFH}^{+}$did not change by the addition of both coinitiators, so ground-state interactions between these 


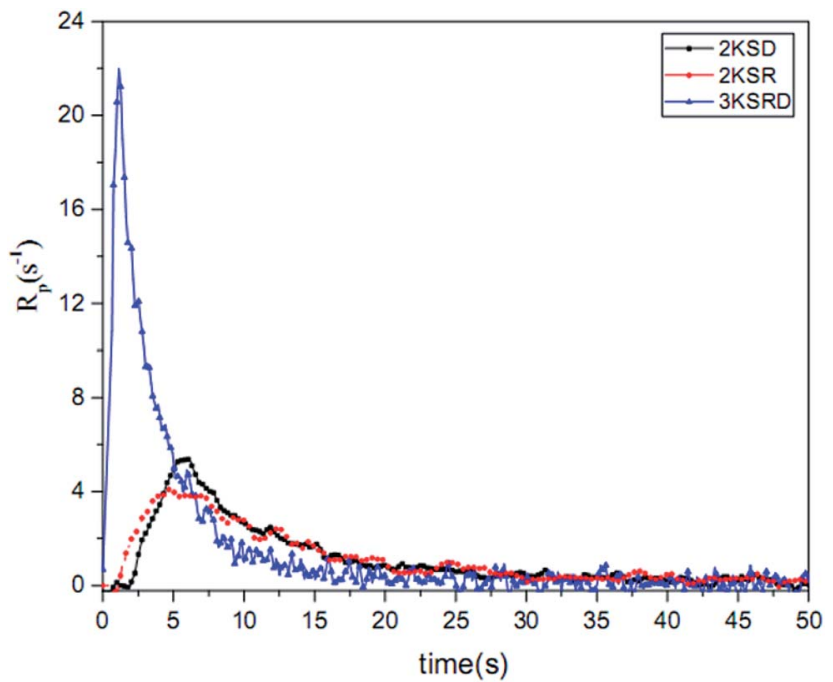

Fig. 10 Polymerization rate vs. time for two- and three-component PIS samples.

components could be discarded. In addition, it can be understood that only $\mathrm{SFH}^{+}$was excited when using visible light. On the other hand, it is well-known that the irradiation of $\mathrm{SFH}^{+}$ does not initiate polymerization solely, thus the polymerization process would involve the excitation of the $\mathrm{SFH}^{+}$followed by further reactions. ${ }^{45}$

It is worth mentioning that according to the transient absorption spectrum of $\mathrm{SFH}^{+}$, there were three distinct peaks at 430, 520 and $820 \mathrm{~nm}$. The peaks at 430 and $820 \mathrm{~nm}$ belong to triplet-triplet absorption of $\mathrm{SFH}^{+}\left({ }^{3} \mathrm{SFH}^{+}\right)$and the peak at $520 \mathrm{~nm}$ belongs to $\mathrm{SFH}^{+}$photobleached species. The absorption peaks of semi-oxidized and semi-reduced form of $\mathrm{SFH}^{+}$ appeared in $420-430 \mathrm{~nm}$ range. ${ }^{54}$

$\mathbf{S F H}^{+} / \mathbf{I O D}^{+}$. To understand the role of each component in active species production, firstly the photoinduced electron transfer (PET) reaction between ${ }^{3} \mathrm{SFH}^{+}$and $\mathrm{IOD}^{+}$was evaluated. The reaction of $\mathrm{SFH}^{+}$triplet state $\left({ }^{3} \mathrm{SFH}^{+}\right)$with diphenyl iodonium hexafluorophosphate as a strong electron acceptor should result in semi-oxidized $\mathrm{SFH}^{+}\left(\mathrm{SFH}^{2+}\right)$. The Gibbs free energy change of this reaction could be determined by using RehmWeller equation:

$$
\Delta G_{\mathrm{ET}}=E_{\mathrm{ox}}(\mathrm{D})-E_{\text {red }}(\mathrm{A})-E_{\mathrm{T}}+C
$$

where $E_{\text {ox }}(\mathrm{D})$ refers to electron donor oxidation potential and $E_{\text {red }}(\mathrm{A})$ is electron acceptor reduction potential, $E_{\mathrm{T}}$ is photoinitiator triplet state energy and $C$ stands for a Coulombic term which is negligible in acetonitrile. Based on the data presented in Table $s 1, \uparrow$ the Gibbs free energy change was found to be $-0.77 \mathrm{eV}$ which indicates the spontaneous nature of the reaction.

Fig. 11 shows the results of LFP analysis for the reaction between ${ }^{3} \mathrm{SFH}^{+}$and $\mathrm{IOD}^{+}$(eqn (6) and (7)). As shown in Fig. 11a, ${ }^{3} \mathrm{SFH}^{+}$was found to decay faster when $\mathrm{IOD}^{+}$concentration increased. Furthermore, the formation of a permanent signal at $520 \mathrm{~nm}$ in Fig. 11b, implied that the concentration of $\mathrm{SFH}^{+}$ decreased due to the reaction between ${ }^{3} \mathrm{SFH}^{+}$and $\mathrm{IOD}^{+}$.

The quenching rate constant $k_{\mathrm{q}}{ }^{3} \mathrm{SFH}^{+} / \mathrm{IOD}^{+}$was calculated to be $5 \times 10^{5} \mathrm{~L} \mathrm{~mol}^{-1} \mathrm{~s}^{-1}$ by using Stern-Volmer plot, which was in agreement with previous reports..$^{42,43}$ One of the products of eqn (7) (IOD) could be dissociated into an active aryl radical (Ph) and a stable molecule (eqn (8)). These results were consistent with the RT-FTIR results: as it is shown in Fig. 9, free radical polymerization of 2 KSD system could reach $60 \%$ final conversion that meant the aryl radicals could efficiently initiate the polymerization.

$$
\begin{gathered}
\mathrm{SFH}^{+} \stackrel{h v}{\rightarrow}{ }^{3} \mathrm{SFH}^{+} \\
{ }^{3} \mathrm{SFH}^{+}+\mathrm{IOD}^{+} \rightarrow \cdot \mathrm{SFH}^{2+}+\mathrm{IOD}^{\cdot} \\
\mathrm{IOD}^{\cdot} \rightarrow \mathrm{Ph}^{\cdot}+\mathrm{PhI}
\end{gathered}
$$

The photobleaching signal of $\mathrm{SFH}^{+}$in the presence of enough amount of $\mathrm{IOD}^{+}$, was followed by increasing the concentration of RSH to investigate the effect of the second coinitiator on the mechanism of three-component PIS. In other words, if there would be a photocyclic reaction, the photobleaching signal of $\mathrm{SFH}^{+}$would be returned to zero. It means that safranin dye in the ground state form was recovered by the reaction between $\left(\mathrm{SFH}^{2+}\right)$ and thiol. However, as can be seen in Fig. s2, $\dagger$ the photobleaching signal of the $\mathrm{SFH}^{+}$decreased when the amount of RSH was increased. This clearly indicated that no reaction occurred to recover $\mathrm{SFH}^{+}$in ground state. Furthermore,
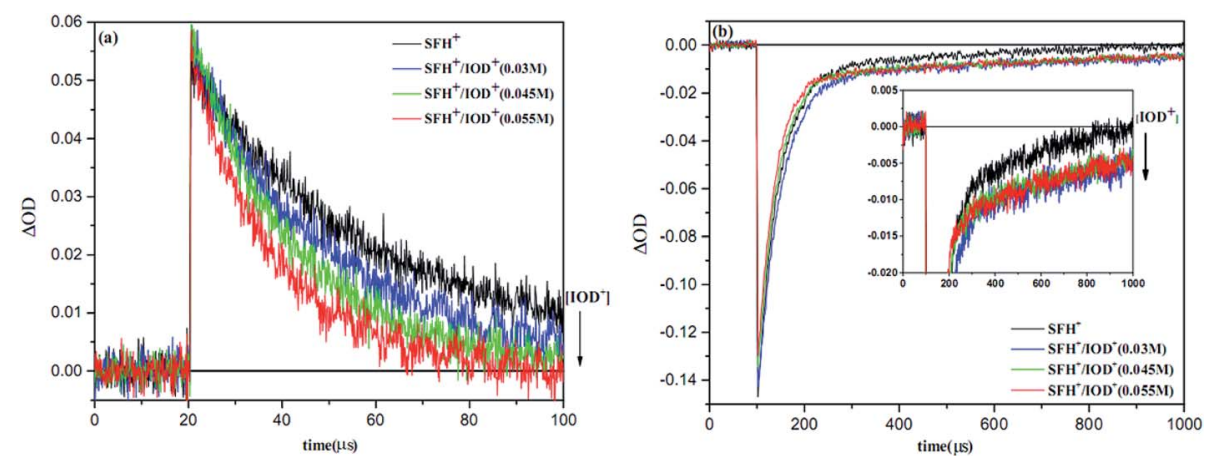

Fig. 11 (a) The decay of triplet-triplet absorption $\left[{ }^{3} \mathrm{SFH}^{+}\right]$measured at $820 \mathrm{~nm}$ and (b) ground state photobleaching of $\left[\mathrm{SFH} \mathrm{H}^{+}\right]$recorded at $520 \mathrm{~nm}$ in the presence of various concentrations of $\mathrm{IOD}^{+}\left(\lambda_{\text {exc }}=518 \mathrm{~nm}, 6-7 \mathrm{~mJ}\right.$ per pulse). 

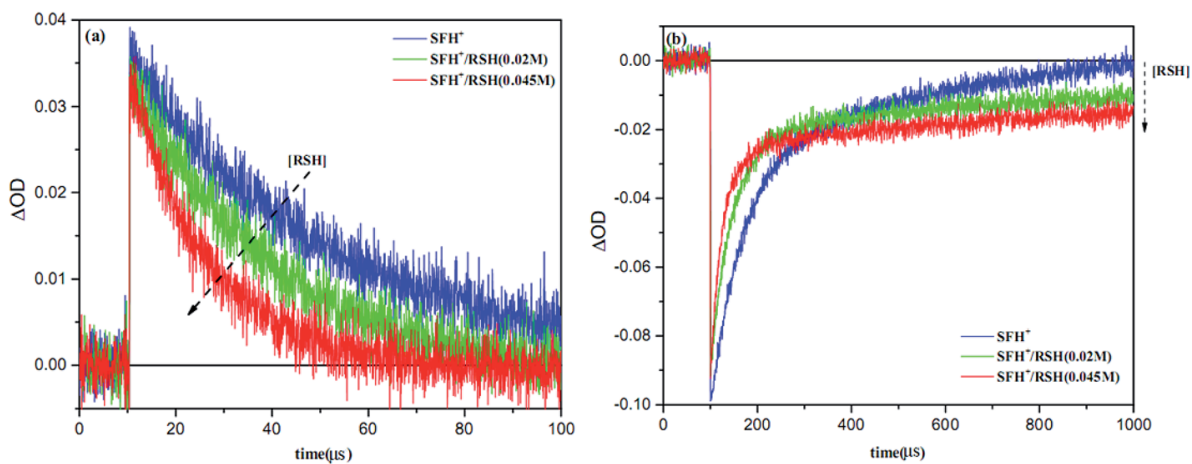

Fig. 12 (a) The decay of triplet-triplet absorption $\left[{ }^{3} \mathrm{SFH}^{+}\right]$measured at $820 \mathrm{~nm}$ and (b) ground state photobleaching of $\left[\mathrm{SFH} \mathrm{H}^{+}\right]$recorded at $520 \mathrm{~nm}$ in the presence of various concentrations of RSH ( $\lambda_{\text {exc }}=518 \mathrm{~nm}, 6-7 \mathrm{~mJ}$ per pulse).

the decrease in the photobleaching signal of $\mathrm{SFH}^{+}$in the presence of RSH could express that there was a parallel reaction between RSH and the residual amount of unreacted ${ }^{3} \mathrm{SFH}^{+}$.

$\mathbf{S F H}^{+} / \mathbf{R S H}$. One of the possible ways of producing active species in the proposed three-component PIS was the reaction between ${ }^{3} \mathrm{SFH}^{+}$and $\mathrm{RSH}$ as the primary photoreaction (eqn (9) and (10)). It seems that the neat electron transfer reaction between ${ }^{3} \mathrm{SFH}^{+}$and $\mathrm{RSH}$ could be ignored due to its positive Gibbs free energy change $(+0.31 \mathrm{eV})$. On the other hand, hydrogen abstraction reaction could occur between ${ }^{3} \mathrm{SFH}^{+}$and RSH as a well-known hydrogen donor. ${ }^{55,56}$ Indeed, as shown in Fig. 12a, ${ }^{3} \mathrm{SFH}^{+}$signal at $820 \mathrm{~nm}$ was effectively quenched by increasing the amounts of RSH and the quenching rate constant $k_{\mathrm{q}}{ }^{3} \mathrm{SFH}^{+} / \mathrm{RSH}$ was calculated to be $7 \times 10^{5} \mathrm{~L} \mathrm{~mol}^{-1} \mathrm{~s}^{-1}$ which was in the same order of magnitude for aliphatic thiols. ${ }^{57}$ The photobleaching signal of $\mathrm{SFH}^{+}$in the presence of $\mathrm{RSH}$ is shown in Fig. 12b. Generation of a permanent signal by adding RSH, would be a confirmation for eqn (10). ${ }^{58,59}$ Thiyl radicals produced in this reaction could initiate the radical polymerization which was in agreement with RT-FTIR results of 2 KSR system.

$$
\begin{gathered}
\mathrm{SFH}^{+} \stackrel{h v}{\rightarrow} \mathrm{SFH}^{+} \\
{ }^{3} \mathrm{SFH}^{+}+\mathrm{RSH}^{\rightarrow} \mathrm{SFH}_{2}{ }^{+}+\mathrm{RS} \cdot \\
\mathrm{SFH}_{2}{ }^{\cdot+}+\mathrm{IOD}^{+} \rightarrow \mathrm{SFH}^{+}+\mathrm{Ph} \bullet+\mathrm{PhI}
\end{gathered}
$$

As shown in Fig. 13, the photobleaching signal of $\mathrm{SFH}^{+}$in the presence of RSH came back to zero when $\mathrm{IOD}^{+}$was added to the system. This feature indicated that $\mathrm{SFH}^{+}$was efficiently recovered during the reaction (eqn (11)). Consequently, it could be concluded that there was a photocyclic reaction which could produce two different radical species (i.e., $\mathrm{RS}^{*}$ and $\mathrm{Ph}^{\circ}$ ) which could both initiate the radical polymerization in a proper manner. Most importantly, synergistic effect of producing more active species and recovery of the photosensitizer in threecomponent PIS improved the polymerization rate and final conversion, as showed RT-FTIR results.

It is worth noting that $\mathrm{SFH}^{+}$acted as a photoabsorber in this system as well which improved the resolution of $3 \mathrm{D}$ printed

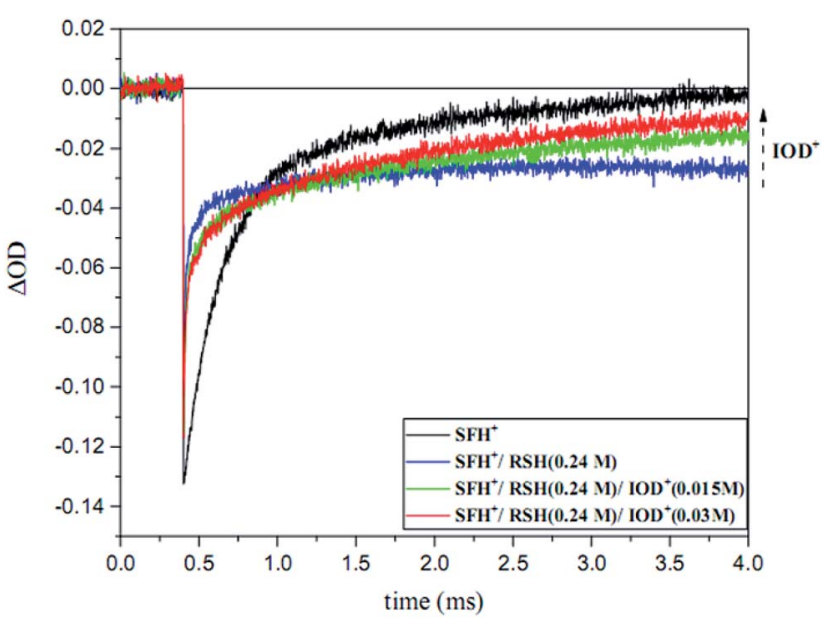

Fig. 13 Ground state photobleaching of $\left[\mathrm{SFH}^{+}\right]$recorded at $520 \mathrm{~nm}$ in the presence of RSH at $0.24 \mathrm{M}$ and various concentration of $\mathrm{IOD}^{+}\left(\lambda_{\text {exc }}\right.$ $=518 \mathrm{~nm}, 6-7 \mathrm{~mJ}$ per pulse).

articles. Therefore, the photocylic behavior of $\mathrm{SFH}^{+}$would also be beneficial from this point of view.

\section{Conclusions}

A three-component photoinitiating system based on safranin was introduced to print complicated geometries by using digital light processing $3 \mathrm{D}$ printing. The following statements can be concluded from this work:

(1) The feasibility of using $\mathrm{SFH}^{+} / \mathrm{RSH} / \mathrm{IOD}^{+}$mixture as an efficient three-component PIS for free radical photopolymerization of diacrylate monomers (i.e., SR349) was demonstrated.

(2) The resolution and shrinkage of DLP 3D printed parts in the presence of $\mathrm{SFH}^{+} / \mathrm{RSH} / \mathrm{IOD}^{+}$and a conventional photoinitiator (i.e., TPO) were compared.

(3) The resolution and shrinkage of DLP 3D printed parts improved remarkably when $\mathrm{SFH}^{+} / \mathrm{RSH} / \mathrm{IOD}^{+}$was used as PIS.

(4) The incorporation of $\mathrm{IOD}^{+}$coinitiator to the mixture of $\mathrm{SFH}^{+}$and $\mathrm{RSH}$ caused the regeneration of $\mathrm{SFH}^{+}$through a photocyclic reaction. 
(5) The reaction mechanism of $\mathrm{SFH}^{+} / \mathrm{RSH}$ was studied by using laser flash photolysis technique for the first time.

\section{Conflicts of interest}

There are no conflicts to declare.

\section{References}

1 T. D. Ngo, A. Kashani, G. Imbalzano, K. T. Q. Nguyen and D. Hui, Additive manufacturing (3D printing): A review of materials, methods, applications and challenges, Composites, Part B, 2018, 143, 172-196, DOI: 10.1016/ j.compositesb.2018.02.012.

2 X. Wang, M. Jiang, Z. Zhou, J. Gou and D. Hui, 3D printing of polymer matrix composites: a review and prospective, Composites, Part B, 2017, 110, 442-458, DOI: 10.1016/ j.compositesb.2016.11.034.

3 S. C. Ligon, R. Liska, J. Stampfl, M. Gurr and R. Mulhaupt, Polymers for 3D Printing and Customized Additive Manufacturing, Chem. Rev., 2017, 117, 10212-10290, DOI: 10.1021/acs.chemrev.7b00074.

4 D. C. Ackland, D. Robinson, M. Redhead, P. V. S. Lee, A. Moskaljuk and G. Dimitroulis, A personalized 3Dprinted prosthetic joint replacement for the human temporomandibular joint: From implant design to implantation, J. Mech. Behav. Biomed. Mater., 2017, 69, 404-411, DOI: 10.1016/j.jmbbm.2017.01.048.

5 A. L. Jardini, M. A. Larosa, R. M. Filho, C. A. D. C. Zavaglia, L. F. Bernardes, C. S. Lambert, D. R. Calderoni and P. Kharmandayan, Cranial reconstruction: 3D biomodel and custom-built implant created using additive manufacturing, J. Cranio-Maxillofacial Surg., 2014, 42, 1877-1884, DOI: 10.1016/j.jcms.2014.07.006.

6 U. Boehm, K. Ruppert and M. Beyer, Production of individual dental prostheses via CAD/CAM and rapid manufacturing/ rapid prototyping based on data of the situation in the mouth obtained by digital means, US 2013/0326878 A1, 2013.

7 R. J. Thomas, Method for automatically creating a denture using laser altimetry to create a digital 3-D oral cavity model and using a digital internet connection to a rapid stereolithographic modeling machine, US 7,153,135 B1, 2006.

8 W. Jia, P. S. Gungor-Ozkerim, Y. S. Zhang, K. Yue, K. Zhu, W. Liu, Q. Pi, B. Byambaa, M. R. Dokmeci, S. R. Shin and A. Khademhosseini, Direct 3D bioprinting of perfusable vascular constructs using a blend bioink, Biomaterials, 2016, 106, 58-68, DOI: 10.1016/j.biomaterials.2016.07.038.

9 X. Cui, K. Breitenkamp, M. G. Finn, M. Lotz and D. D. D'Lima, Direct Human Cartilage Repair Using ThreeDimensional Bioprinting Technology, Tissue Eng., Part A, 2012, 18, 1304-1312, DOI: 10.1089/ten.tea.2011.0543.

10 N. K. Dey, Additive manufacturing laser deposition of Ti-6Al-4V for aerospace repair application, 2014.

11 J. E. Grady, W. J. Haller, P. E. Poinsatte, M. C. Habig and S. L. Schnulo, A Fully Nonmetallic Gas Turbine Engine Enabled by Additive Manufacturing Part I: System Analysis,
Component Identification, Additive Manufacturing, and Testing of Polymer Composites, 2015.

12 S. Shan, S. H. Kang, J. R. Raney, P. Wang, L. Fang, F. Candido, J. A. Lewis and K. Bertoldi, Multistable Architected Materials for Trapping Elastic Strain Energy, Adv. Mater., 2015, 27, 4296-4301, DOI: 10.1002/ adma.201501708.

13 M. Xia and J. Sanjayan, Method of formulating geopolymer for 3D printing for construction applications, Mater. Des., 2016, 110, 382-390, DOI: 10.1016/j.matdes.2016.07.136.

14 Q. Mu, L. Wang, C. K. Dunn, X. Kuang, F. Duan, Z. Zhang, H. J. Qi and T. Wang, Digital light processing 3D printing of conductive complex structures, Addit. Manuf., 2017, 18, 74-83, DOI: 10.1016/j.addma.2017.08.011.

15 Statista Global, 3D printing market size 2013-2021 / Statistic, Statista, 2019. https://www.statista.com/statistics/796237/ worldwide-forecast-growth-3d-printing-market/.

16 R. Ding, Y. Du, R. B. Goncalves, L. F. Francis and T. M. Reineke, Sustainable near UV-curable acrylates based on natural phenolics for stereolithography 3D printing, Polym. Chem., 2019, 10, 1067-1077, DOI: 10.1039/ c8py01652f.

17 Y. Pan, C. Zhou and Y. Chen, A fast mask projection stereolithography process for fabricating digital models in minutes, J. Eng. Ind., 2012, 134, 051011, DOI: 10.1115/ 1.4007465 .

18 A. Vitale and J. Cabral, Frontal Conversion and Uniformity in 3D Printing by Photopolymerisation, Materials, 2016, 9, 760, DOI: $10.3390 / \mathrm{ma} 9090760$.

19 J. Borrello, P. Nasser, J. Iatridis and K. D. Costa, 3D printing a mechanically-tunable acrylate resin on a commercial DLPSLA printer, Addit. Manuf., 2018, 23, 374-380, DOI: 10.1016/ j.addma.2018.08.019.

20 H. Gong, B. P. Bickham, A. T. Woolley and G. P. Nordin, Custom 3D printer and resin for $18 \mu \mathrm{m} \times 20 \mu \mathrm{m}$ microfluidic flow channels, Lab Chip, 2017, 17, 2899-2909, DOI: $10.1039 / \mathrm{c} 7 \mathrm{lc00644f}$.

21 M. M. Zabti, Effects of Light Absorber on Micro Stereolithography Parts, Doctoral dissertation, University of Birmingham, 2012.

22 M. P. Lee, G. J. T. Cooper, T. Hinkley, G. M. Gibson, M. J. Padgett and L. Cronin, Development of a 3D printer using scanning projection stereolithography, Sci. Rep., 2015, 5, 9875, DOI: 10.1038/srep09875.

23 L. Ge, L. Dong, D. Wang, Q. Ge and G. Gu, A digital light processing $3 \mathrm{D}$ printer for fast and high-precision fabrication of soft pneumatic actuators, Sens. Actuators, A, 2018, 273, 285-292, DOI: 10.1016/j.sna.2018.02.041.

24 K. Kowsari, B. Zhang, S. Panjwani, Z. Chen, H. Hingorani, S. Akbari, N. X. Fang and Q. Ge, Photopolymer formulation to minimize feature size, surface roughness, and stairstepping in digital light processing-based threedimensional printing, Addit. Manuf., 2018, 24, 627-638, DOI: 10.1016/j.addma.2018.10.037.

25 S. Zissi, A. Bertsch, J. Y. Jézéquel, S. Corbel, D. J. Lougnot and J. C. André, Stereolithography and microtechniques, 
Microsyst. Technol., 1996, 2, 97-102, DOI: 10.1007/ BF02447758.

26 J.-W. Choi, R. B. Wicker, S.-H. Cho, C.-S. Ha and S. Lee, Cure depth control for complex 3D microstructure fabrication in dynamic mask projection microstereolithography, Rapid Prototyp. J., 2009, 15, 59-70, DOI: 10.1108/ 13552540910925072.

27 R. Bail, J. Y. Hong and B. D. Chin, Effect of a red-shifted benzotriazole UV absorber on curing depth and kinetics in visible light initiated photopolymer resins for 3D printing, J. Ind. Eng. Chem., 2016, 38, 141-145, DOI: 10.1016/ j.jiec.2016.04.017.

28 M. M. Zabti, M. E. Abid and M. A. Nwir, Effects on Dimensional Accuracy of Microstereolithographically Machined Parts after Addition of Light Absorber, The International Journal of Engineering and Information Technology, 2015, 2, 12-17.

29 Y. Jian, Y. He, T. Jiang, C. Li, W. Yang and J. Nie, Volume shrinkage of UV-curable coating formulation investigated by real-time laser reflection method, J. Coat. Technol. Res., 2013, 10, 231-237, DOI: 10.1007/s11998-012-9446-2.

30 B. Steyrer, P. Neubauer, R. Liska and J. Stampfl, Visible Light Photoinitiator for 3D-Printing of Tough Methacrylate Resins, Materials, 2017, 10, 1445-1456, DOI: 10.3390/ma10121445.

31 S. Schoerpf, Y. Catel, N. Moszner, C. Gorsche and R. Liska, Enhanced reduction of polymerization-induced shrinkage stress via combination of radical ring opening and addition fragmentation chain transfer, Polym. Chem., 2019, 10, 1357-1366, DOI: 10.1039/c8py01540f.

32 A. Chiappone, S. Lantean, I. Roppolo, M. Sangermano and C. F. Piri, Development of new hybrid acrylic/epoxy DLP-3D printable materials, Inventions, 2018, 3, 29-41, DOI: 10.3390/inventions3020029.

33 X. Allonas, A. Ibrahim, V. Charlot, M. Retailleau, F. Karasu and C. Croutxe-Barghorn, Development of New Photoinitiating Systems for Depth Curing of Thick Materials, J. Photopolym. Sci. Technol., 2015, 28, 25-29, DOI: 10.2494/photopolymer.28.25.

34 P. Xiao, J. Zhang, F. Dumur, M. A. Tehfe, F. Morlet-Savary, B. Graff, D. Gigmes, J. P. Fouassier and J. Lalevée, Visible light sensitive photoinitiating systems: Recent progress in cationic and radical photopolymerization reactions under soft conditions, Prog. Polym. Sci., 2014, 41, 32-66, DOI: 10.1016/j.progpolymsci.2014.09.001.

35 J. P. Fouassier and J. Lalevee, Photoinitiators for Polymer Synthesis: Scope, Reactivity, and Efficiency, John Wiley \& Sons, 2012.

36 H. Kitano, K. Ramachandran and A. B. Scranton, Free radical shadow cure initiated using two-component and threecomponent initiator systems, Int. J. Photoenergy, 2012, 2012, 213846.

37 A. Ibrahim, B. El Fouhaili, A. C. Yong, C. Ley, X. Allonas and C. Carré, Optimization of a Safranine O three-component photoinitiating system for use in holographic recording, Can. J. Chem., 2015, 93, 1345-1353, DOI: 10.1139/cjc-20140606.
38 D. Kim and A. Scranton, The role of diphenyl iodonium salt (DPI) in three-component photoinitiator systems containing methylene blue (MB) and an electron donor, J. Polym. Sci., Part A: Polym. Chem., 2004, 42, 5863-5871, DOI: 10.1002/ pola.20426.

39 C. Ley, J. Christmann, A. Ibrahim, L. H. Di Stefano and X. Allonas, Tailoring of organic dyes with oxidoreductive compounds to obtain photocyclic radical generator systems exhibiting photocatalytic behavior, Beilstein J. Org. Chem., 2014, 10, 936-947, DOI: 10.3762/bjoc.10.92.

$40 \mathrm{~W}$. D. Cook and F. Chen, Enhanced visible radiation photopolymerization of dimethacrylates with the three component thioxanthone (CPTXO)-amine-iodonium salt system, Polym. Chem., 2015, 6, 1325-1338, DOI: 10.1039/ c4py01561d.

41 J. Shao, Y. Huang and Q. Fan, Visible light initiating systems for photopolymerization: status, development and challenges, Polym. Chem., 2014, 5, 4195-4210, DOI: 10.1039/C4PY00072B.

42 M. L. Gomez, C. M. Previtali and H. A. Montejano, Phenylonium salts as third component of the photoinitiator system safranine O/triethanolamine: A comparative study in aqueous media, Polymer, 2007, 48, 2355-2361, DOI: 10.1016/j.polymer.2007.02.015.

43 M. L. Gomez, V. Avila, H. A. Montejano and C. M. Previtali, A mechanistic and laser flash photolysis investigation of acrylamide polymerization photoinitiated by the three component system safranine-T/triethanolamine/ diphenyliodonium chloride, Polymer, 2003, 44, 2875-2881, DOI: 10.3390/ma9090760.

44 A. Ibrahim, X. Allonas, C. Ley, K. Kawamura, H. Berneth, F. K. Bruder, T. Fäcke, R. Hagen, D. Hönel, T. Rölle, G. Walze and M. S. Weiser, High performance photoinitiating systems for holography recording: Need for a full control of primary processes, Chem. - Eur. J., 2014, 20, 15102-15107, DOI: 10.1002/chem.201404072.

45 W. G. Santos, C. C. Schmitt and M. G. Neumann, Polymerization of HEMA photoinitiated by the Safranine/ diphenylborinate system, J. Photochem. Photobiol., A, 2013, 252, 124-130, DOI: 10.1016/j.jphotochem.2012.12.007.

46 D. K. Patel, A. H. Sakhaei, M. Layani, B. Zhang, Q. Ge and S. Magdassi, Highly Stretchable and UV Curable Elastomers for Digital Light Processing Based 3D Printing, Adv. Mater., 2017, 29, 1606000-1606006, DOI: 10.1002/ adma.201606000.

47 D. U. Shah and P. J. Schubel, Evaluation of cure shrinkage measurement techniques for thermosetting resins, Polym. Test., 2010, 29, 629-639, DOI: 10.1016/ j.polymertesting.2010.05.001.

48 J. Christmann, S. Shi, A. Ibrahim, C. Ley, C. CroutxeBarghorn, M. Bessieres and X. Allonas, Mechanistic Investigation of a Dual Bicyclic Photoinitiating System for Synthesis of Organic - Inorganic Hybrid Materials, J. Phys. Chem. B, 2017, 121, 1972-1981, DOI: 10.1021/ acs.jpcb.6b11829.

49 H. Okamura, S. Niizeki, T. Ochi and A. Matsumoto, UV Curable Formulations for UV-C LEDs, J. Photopolym. Sci. 
Technol., 2016, 29, 99-104, DOI: 10.2494/ photopolymer.29.99.

50 H. Lu, J. W. Stansbury and C. N. Bowman, Impact of Curing Protocol on conversion and shrinkage stress, J. Dent. Res., 2005, 84, 822-826, DOI: 10.1177/154405910508400908.

51 N. Emami and K. J. M. Soderholm, Influence of light-curing procedures and photo-initiator/co-initiator composition on the degree of conversion of light-curing resins, J. Mater. Sci.: Mater. Med., 2005, 16, 47-52, DOI: 10.1007/s10856005-6445-1.

52 A. Al Mousawi, P. Garra, X. Sallenave, F. Dumur, J. Toufaily, T. Hamieh, B. Graff, D. Gigmes, J. P. Fouassier and J. Lalevée, $\pi$-Conjugated Dithienophosphole Derivatives as High Performance Photoinitiators for 3D Printing Resins, Macromolecules, 2018, 51, 1811-1821, DOI: 10.1021/ acs.macromol.8b00044.

53 A. Ibrahim, L. Di Stefano, O. Tarzi, H. Tar, C. Ley and X. Allonas, High-performance photoinitiating systems for free radical photopolymerization. Application to holographic recording, Photochem. Photobiol., 2013, 89, 1283-1290, DOI: 10.1111/php.12132.

54 M. F. Broglia, M. L. Gomez, S. G. Bertolotti, H. A. Montejano and C. M. Previtali, Photophysical properties of safranine and phenosafranine A comparative study by laser flash photolysis and laser induced optoacoustic spectroscopy, $J$. Photochem. Photobiol., A, 2005, 173, 115-120, DOI: 10.1016/ j.jphotochem.2005.01.010.

55 E. Andrzejewska, D. Zych-Tomkowiak, M. Andrzejewski, G. L. Hug and B. Marciniak, Heteroaromatic thiols as coinitiators for type II photoinitiating systems based on camphorquinone and isopropylthioxanthone, Macromolecules, 2006, 39, 3777-3785, DOI: 10.1021/ ma060240k.

56 S. Dadashi-Silab, C. Aydogan and Y. Yagci, Shining a Light on an Adaptable Photoinitiator: Advances in Photopolymerizations Initiated by Thioxanthones, Polym. Chem., 2015, 6, 6595-6615, DOI: 10.1039/C5PY01004G.

57 J. Lalevee, F. Morlet-savary, M. El Roz, X. Allonas and J. P. Fouassier, Thiyl Radical Generation in Thiol or Disulfide Containing Photosensitive Systems, Macromol. Chem. Phys., 2009, 210, 311-319, DOI: 10.1002/ macp. 200800566.

58 S. N. Guha and J. P. Mittal, Pulse radiolysis study of oneelectron reduction of safranine T, J. Chem. Soc., Faraday Trans., 1997, 93, 3647-3652, DOI: 10.1039/A702927F.

59 C. E. Baumgartner, H. H. Richtol and D. A. Aikens, Transient photochemistry of safranin-O, Photochem. Photobiol., 1981, 34, 17-22. 